\title{
DESIGNING COCOA TRANSPORT NETWORKS USING A SUPPLY CHAIN NETWORK EQUILIBRIUM MODEL WITH THE BEHAVIOUR OF FREIGHT CARRIERS
}

\author{
Zukhruf FEBRI ${ }^{1}$, Tadashi YAMADA ${ }^{2}$ and Eiichi TANIGUCHI ${ }^{3}$ \\ ${ }^{1}$ Member of JSCE, Student, Dept. of Urban Man., University of Kyoto \\ (Kyotodaigaku Katsura C1, Kyoto 615-8540, Japan) \\ E-mail: febri.zukhruf@kiban.kuciv.kyoto-u.ac.jp \\ ${ }^{2}$ Member of JSCE, Associate Professor, Dept. of Urban Man., University of Kyoto \\ (Kyotodaigaku Katsura C1, Kyoto 615-8540, Japan) \\ E-mail: t.yamada@kiban.kuciv.kyoto-u.ac.jp \\ ${ }^{3}$ Member of JSCE, Professor, Dept. of Urban Man., University of Kyoto \\ (Kyotodaigaku Katsura C1, Kyoto 615-8540, Japan) \\ E-mail: taniguchi@kiban.kuciv.kyoto-u.ac.jp
}

\begin{abstract}
This paper presents a multi-channelled supply chain network equilibrium (SCNE) model with the behaviour of freight carriers, which is developed to represent the trading chain of cocoa in Sulawesi, Indonesia. The model takes into account the behaviour of local collectors, local traders, exporters, and freight carriers. Utilising this SCNE in the lower level, a combinatorial optimisation is undertaken in the upper level within the framework of mathematical programmes with equilibrium constraints, where a suitable set of transport network improvement actions is selected from a number of possible actions for improving the efficiency of cocoa supply chain network (SCN). The upper level is solved with a modified probability-based discrete binary particle swarm optimisation. Finally, the model is applied to an actual cocoa SCN in Sulawesi for investigating the impact of transport measures to the international trading of cocoa.
\end{abstract}

Key Words : cocoa transport, supply chain network, multiple channels, freight carriers' behaviour

\section{INTRODUCTION}

Indonesia is the 3rd largest cocoa producers in the world, which accounted for more than $10 \%$ of total world production ${ }^{1)}$. The area of cocoa plantations in Indonesia reaches 992,448 hectares, in which it is mostly planted in Sulawesi Island ${ }^{2}$. As export commodities, cocoa is considerably valuable for Indonesian economy, where it has contributed at approximately $\$ 600-700$ million per year, and created job opportunities for 400,000 people ${ }^{3)}$. However, the inefficiencies in trading chain and logistics system (e.g., poor road infrastructure, and insufficient port infrastructure) significantly affect the profit margins of Indonesian business owners ${ }^{4), 5)}$.

Supply chain network (SCN) represents the linkage among the economic entities and the resulting their behavioural interactions. Nagurney et al. ${ }^{6}$ commenced multi-tiered supply chain network equi- librium (SCNE) modelling, which incorporates decentralised decision-making by multiple agents on an SCN and takes into account their behavioural interactions. In this model, the decision-makers are manufacturers, retailers, and consumers, who compete within a tier but cooperate between tiers. Therefore, the product can flow from the manufactures to the consumers via transactions. The model can also provide several valuable outputs for the $\mathrm{SCN}$, such as the amount of the products produced and transacted, and the price of the products. Recently, there has been a lot of significant effort to expand the SCNE model (see the comprehensive review in Yamada et al. ${ }^{7}$ ), including Yamada et al. ${ }^{7), 8)}$ remarkably initiated a SCNE model, within which the behaviours of freight carriers is encompassed. The model is most related to this research among existing SCNE models, and enables to investigate the impacts of freight transport-related policies on the 
whole supply chain of a product.

However, the existing SCNE models are commonly oriented to industrial products (e.g., manufactured and electronics products), whereas the supply chain of agricultural products remains important in terms of consumption and monetary values ${ }^{9)-11)}$. In addition, the integration of agricultural production and distribution along the chain is becoming more and more important, due to the growing global competition $^{12)}$, and the greater distances between the locations of producers and consumers ${ }^{13)}$. As indicated by Ahumada and Villalobos ${ }^{12)}$, there have been few models that represent the fully integration of SCNs of agricultural product.

This paper formulates a multi-channelled SCNE model with the behaviour of freight carriers. Unlike the existing SCNE-related papers, this model is first dedicated to the supply chain of cocoa, which might be typical to other agricultural product chains. The chain needs to involve local collectors, local traders, exporters, and freight carriers ${ }^{14), 15)}$. In the actual conditions, the local collectors can make transaction not only with the local traders, but also directly with the exporters, and hence, this SCNE model incorporates such multiple channels. In addition, as the local collectors are not involved producing process, the collection cost needs to be included, which is not found out in the preceding SCNE research.

Furthermore, several studies ${ }^{4), 16)}$ also reported the importance of transport infrastructure for supporting the agricultural trading chain, since it significantly influences the costs for moving the agricultural products. Recently, Yu and Nagurney ${ }^{17)}$ developed a network-based food supply chain model under oligopolistic competition and perishability, with a focus on fresh produce. Although it has incorporated the characteristic of agricultural products within SCNE, the model has not explicitly considered the behaviour of freight carriers. Therefore, the effects of changes in the transport network on agricultural SCNs cannot be investigated. As different from preceding papers, the model to be presented in this paper takes into account the behaviour of freight carriers and enables to investigate the impacts of transport network-related (TN-related) policies on the supply chain of an agricultural product like cocoa.

Under the assumption of SCNE, this paper also proposes a discrete optimisation model within the framework of mathematical programmes with equilibrium constraints (MPEC). The model could allow to evaluate the decision-making in a freight transport network as well as to select the suitable actions in it to improve the efficiency of SCNs. The actions consist of improving existing roads, establishing new roads, improving seaports and establishing new railways, where the most feasible set of actions is selected. This model can therefore be recognised as a discrete network design problem (DNDP). In fact, a large number of researches have been conducted on DNDP over the past three decades ${ }^{18)-22)}$. Nevertheless, to our knowledge, there has been no attempt to optimally design cocoa transport networks looking over the entire cocoa SCN as well as to model it within the framework of SCNE. Furthermore, the main results of such network analyses strongly relate to decision support for the transport agency (i.e., planners and administrators/government) for designing the freight TN by improving the efficiency of SCN.

Within the modelling framework of MPEC, the multi-channelled cocoa SCNE model is incorporated in the lower level, and the upper level corresponds to a combinatorial optimisation problem. The upper level involves binary (0-1) decision variables, representing whether or not a candidate for freight transport improvement action is chosen. The MPEC is an NP-complete problem due to the parameterised variational inequality (VI) constraints. Thus, metaheuristics-based solution procedures, which can handle combinatorial optimisation problems in relatively shorter computational times with higher quality of solutions, need to be applied to the upper level. Specifically, a modified probability-based discrete binary particle swarm optimisation (MPBPSO) ${ }^{23)}$ is applied as a solution technique in the upper level.

The rest of the paper is organised as follows. In the following section, the overall modelling framework is described, and the formulation of the lower-level cocoa SCNE is given. In section 3, the model developed is numerically tested to validate its performance using a cocoa SCN in Sulawesi, Indonesia. The applicability of the model will be tested using the cocoa SCN to explore the implications of how to expand the TN. Finally, in section 5, there is a summary of the methodologies, results, and analyses.

\section{NETWORK DESIGN MODEL}

\section{(1) Overall framework}

The MPEC model consists of two levels. The lower level involves the multi-channelled SCNE, which is able to estimate the prices of cocoa beans (hereafter, simply referred to as cocoa) and the amount of cocoa transacted (i.e., those transported or distributed). The upper level optimises the combination of improvement actions for freight transport. The solutions derived in both levels influence with each other.

The model can be formulated as follows, where the term $\langle\bullet, \bullet\rangle$ represents the inner product in $\mathrm{N}$-dimensional Euclidean space, and equilibrium solutions are denoted by “*”. 


$$
\begin{gathered}
\operatorname{Max} P\left(u, Z^{*}\right) \\
u \\
\text { subject to }(u, Z) \in K \\
\left\langle G\left(u, Z^{*}\right), Z-Z^{*}\right\rangle \geq 0
\end{gathered}
$$

where,

$u \quad:$ vector of the set of TN improvement actions,

$Z$ : vector of state variables on the $\mathrm{SCN}$,

$K \quad:$ non-empty feasible space.

$P\left(u, Z^{*}\right)$ denotes an objective function in the upper level, which is a combinatorial optimisation problem with $0-1$ variables so that $P\left(u, Z^{*}\right)$ is maximised. $G\left(u, Z^{*}\right)$ is a vector valued mapping being influenced by both the decision and state variables. Constraint (2) corresponds to each variable condition and constraint (3) to SCNE (specifically, VI (24)). Both constraints make the lower level.

\section{(2) SCNE at lower level}

The lower level involves the multi-channelled cocoa supply chain network model, which is developed based on the SCNE model with the behaviours of freight carriers $^{8)}$, where some modifications are undertaken to fit multi-channelled cocoa SCNs.

The decision-makers on the supply side (i.e., local collectors, local traders, exporters, and freight carriers) are concerned only with profit maximisation. To represent the SCN with multiple channels, the model allows the local collectors to transact not only with the local traders, but also directly with the exporters. As depicted in Fig.1, let's consider $I$ local collectors collecting cocoa from farmers/growers, which is then shipped to $J$ local traders or $K$ exporters. The local traders, in turn, ship cocoa to $K$ exporters. Finally, the exporters offer cocoa to the consumers, which is associated with $L$ demand markets. Cocoa is transported by $H$ freight carriers. A typical local collector is denoted by $i$, a typical local trader by $j$, a typical exporter by $k$, a typical demand market by $l$, and a typical freight carrier by $h$.

\section{a) The behaviour of local collectors and their} optimality conditions

The local collectors purchase and collect cocoa beans from farmers or growers, which is then shipped to the local traders or the exporters. They play important roles in cocoa supply chain, since farmers, at least in Sulawesi, are mostly not able to sell directly to the local traders or the exporters due to insufficient capital. The local collectors are profit-maximisers and the optimisation problem of local collector $i$ is given by:

$$
\begin{aligned}
& \underset{Q_{i}^{1}, Q_{i}^{2}}{\operatorname{Max}} \sum_{j=1}^{J} \rho_{i j}^{1^{*}} \sum_{h=1}^{H} q_{h i j}+\sum_{k=1}^{K} \rho_{i k}^{2^{*}} \sum_{h=1}^{H} q_{h i k} \\
& -f_{i}\left(Q^{1}, Q^{2}\right)-c_{i}\left(Q^{1}, Q^{2}\right)
\end{aligned}
$$

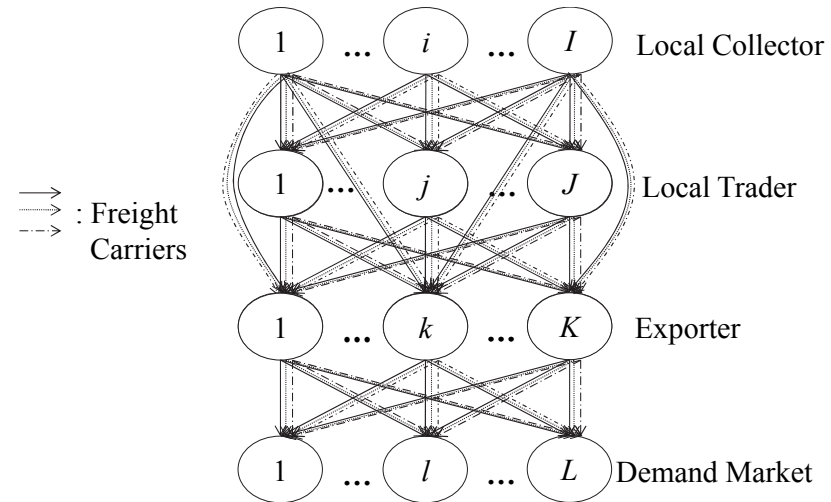

Fig.1 Description of cocoa SCN.

$$
\begin{aligned}
& -g_{i}\left(Q^{1}, Q^{2}\right)-\sum_{j=1}^{J} c_{i j}\left(Q^{1}\right)-\sum_{k=1}^{K} c_{i k}\left(Q^{2}\right) \\
& -\sum_{h=1}^{H} \sum_{j=1}^{J} \rho_{h i j}^{1^{*}} q_{h i j}-\sum_{h=1}^{H} \sum_{k=1}^{K} \rho_{h i k}^{2^{*}} q_{h i k}
\end{aligned}
$$

subject to $q_{h i j} \geq 0 \quad \forall h, j$

$$
q_{h i k} \geq 0 \quad \forall h, k
$$

where,

$\rho_{i j}^{1}$

$\rho_{i k}^{2}$

$q_{h i j}$

$q_{\text {hik }}$

: price charged for cocoa by local collector $i$ to local trader $j$,

: price charged for cocoa by local collector $i$ to exporter $k$,

: amount of cocoa transacted/transported from local collector $i$ to local trader $j$ by freight carrier $h$,

: amount of cocoa transacted/transported from local collector $i$ to exporter $k$ by freight carrier $h$,

$f_{i}\left(Q^{1}, Q^{2}\right) \quad$ : collection cost to local collector $i$,

$c_{i}\left(Q^{1}, Q^{2}\right) \quad:$ handling/inventory costs to local collector $i$,

$g_{i}\left(Q^{1}, Q^{2}\right) \quad$ : facility cost of local collector $i$,

$c_{i j}\left(Q^{1}\right) \quad:$ transaction cost incurred between local collector $i$ and local trader $j$,

$c_{i k}\left(Q^{2}\right)$

$\rho_{h i j}^{1}$

: transaction cost incurred between local collector $i$ and exporter $k$,

: carriage charged by freight carrier $h$ for transporting cocoa between local collector $i$ and local trader $j$,

$\rho_{\text {hik }}^{2} \quad:$ carriage charged by freight carrier $h$ for transporting cocoa between local collector $i$ and exporter $k$.

$Q_{i}^{1} \quad: H J$-dimensional vector with component hij denoted by $q_{h i j}$,

$Q_{i}^{2} \quad: H K$-dimensional vector with component hik denoted by $q_{h i k}$,

: HIJ-dimensional vector with component $h i j$ denoted by $q_{h i j}$,

: HIK-dimensional vector with component hik denoted by $q_{h i k}$.

A local collector $i$ is faced with a han- 
dling/inventory cost, which may be associated with the cost of holding cocoa in stock, for example, loading/unloading, sorting, drying, packaging and storage. Each pair of local collector $i$ and local trader $j$ is associated with transaction cost denoted by $c_{i j}$. A local collector $i$ may also transact directly with the exporter $k$ with transaction cost denoted by $c_{i k}$. It is related to the expenses incurred in making an economic exchange, except the price of the product. In addition, each local collector incurs collection cost, which relates to the expenses for collecting cocoa from farmers or growers. Facility cost, denoted by $g_{i}$, includes the expenditure for operating, improving, maintaining the local collector facilities, and its usage costs. The revenue, in turn, is equal to the price that the local collector charges for cocoa times the total quantity purchased of cocoa from the local collector.

Assuming that the collection cost functions, handling/inventory cost functions, facility cost functions and transaction cost functions are continuous and convex, the optimality conditions for all local collectors can simultaneously be expressed as the following VI (6): determine $\left(Q^{1 *}, Q^{2^{*}}\right) \in R_{+}^{H I J+H I K}$, which satisfies:

$$
\begin{aligned}
& \sum_{h=1}^{H} \sum_{i=1}^{I} \sum_{j=1}^{J}\left[\frac{\partial f_{i}\left(Q^{1^{*}}, Q^{2^{*}}\right)}{\partial q_{h i j}}+\frac{\partial c_{i}\left(Q^{1^{*}}, Q^{2^{*}}\right)}{\partial q_{h i j}}\right. \\
& \quad+\frac{\partial g_{i}\left(Q^{1^{*}}, Q^{2^{*}}\right)}{\partial q_{h i j}}+\frac{\partial c_{i j}\left(Q^{1^{*}}\right)}{\partial q_{h i j}} \\
& \left.\quad+\rho_{h i j}^{1^{*}}-\rho_{i j}^{1^{*}}\right] \times\left[q_{h i j}-q_{h i j}^{*}\right] \\
& +\sum_{h=1}^{H} \sum_{i=1}^{I} \sum_{k=1}^{K}\left[\frac{\partial f_{i}\left(Q^{1^{*}}, Q^{2^{*}}\right)}{\partial q_{h i k}}+\frac{\partial c_{i}\left(Q^{1^{*}}, Q^{2^{*}}\right)}{\partial q_{h i k}}\right. \\
& +\frac{\partial g_{i}\left(Q^{1^{*}}, Q^{2^{*}}\right)}{\partial q_{h i k}}+\frac{\partial c_{i k}\left(Q^{2^{*}}\right)}{\partial q_{h i k}} \\
& \left.+\rho_{h i k}^{2^{*}}-\rho_{i k}^{2^{*}}\right] \times\left[q_{h i k}-q_{h i k}^{*}\right] \geq 0 \\
& \forall\left(Q^{1}, Q^{2}\right) \in R_{+}^{H I J+H I K}
\end{aligned}
$$

\section{b) The behaviour of local traders and their op-} timality conditions

The local traders, in turn, must determine not only the amount of cocoa that they wish to obtain from the local collectors but also those purchased by the exporters in order to maximise their profits. Assuming that the local traders are also profit-maximisers, the optimisation problem of a local trader $j$ is given by:

$$
\begin{aligned}
& \operatorname{Max}_{Q_{j}^{1}, Q_{j}^{3}} \sum_{k=1}^{K} \rho_{j k}^{3^{*}} \sum_{h=1}^{H} q_{h j k}-c_{j}\left(Q^{1}\right)-g_{j}\left(Q^{1}\right) \\
& -\sum_{k=1}^{K} c_{j k}\left(Q^{3}\right)-\sum_{h=1}^{H} \sum_{k=1}^{K} \rho_{h j k}^{3^{*}} q_{h j k}
\end{aligned}
$$

$$
\begin{aligned}
& -\sum_{i=1}^{I} \rho_{i j}^{1^{*}} \sum_{h=1}^{H} q_{h i j} \\
& \text { subject to } \quad \sum_{h=1}^{H} \sum_{k=1}^{K} q_{h j k} \leq \sum_{h=1}^{H} \sum_{i=1}^{I} q_{h i j} \\
& \qquad q_{h i j} \geq 0 \forall h, i, \quad q_{h j k} \geq 0 \forall h, k
\end{aligned}
$$

where,

$\rho_{j k}^{3} \quad$ : sales price charged by local trader $j$ to exporter $k$,

$q_{h j k} \quad:$ amount of cocoa transacted/transported from local trader $j$ to exporter $k$ by freight carrier $h$,

$c_{j}\left(Q^{1}\right)$ : handling/inventory costs to local trader $j$, $g_{j}\left(Q^{1}\right)$ : facility cost to local trader $j$,

$c_{j k}\left(Q^{3}\right)$ : transaction cost incurred between local trader $j$ and exporter $k$,

$\rho_{h j k}^{3} \quad$ : carriage charged by freight carrier $h$ for transporting cocoa between local trader $j$ and exporter $k$.

$Q_{j}^{1} \quad: H I$-dimensional vector with component hij denoted by $q_{h i j}$,

$Q_{j}^{3} \quad: H K$-dimensional vector with component hjk denoted by $q_{h j k}$,

$Q^{3} \quad: H J K$-dimensional vector with component hjk denoted by $q_{h j k}$.

Objective function (7) indicates that the profit of local trader $j$ is maximised, which can be derived by the revenues minus handling/inventory costs, facility cost, transaction cost, transport cost and the payout to the local collectors. Constraint (8) simply expresses the fact that local traders cannot purchase more cocoa from a local collector than is available in stock. Constraint (9) represents the nonnegativity assumption on the variables.

Assuming that the handling/inventory cost functions, facility cost functions and transaction cost functions are continuously differentiable and convex, then the optimality conditions for all local traders simultaneously coincide with the solution of the following VI (10): determine $\left(Q^{1^{*}}, Q^{3^{*}} \gamma^{*}\right)$ $\in R_{+}^{H I J+H J K+K}$ which satisfies:

$$
\begin{aligned}
& \sum_{h=1}^{H} \sum_{i=1}^{I} \sum_{j=1}^{J}\left[\frac{\partial c_{j}\left(Q^{1^{*}}\right)}{\partial q_{h i j}}+\frac{\partial g_{j}\left(Q^{1^{*}}\right)}{\partial q_{h i j}}\right. \\
& \left.+\rho_{i j}^{1^{*}}-\gamma_{j}^{*}\right] \times\left[q_{h i j}-q_{h i j}^{*}\right] \\
& +\sum_{h=1}^{H} \sum_{j=1}^{J} \sum_{k=1}^{K}\left[-\rho_{j k}^{3^{*}}+\frac{\partial c_{j k}\left(Q^{3^{*}}\right)}{\partial q_{h j k}}\right. \\
& \left.+\rho_{h j k}^{3 *}+\gamma_{j}^{*}\right] \times\left[q_{h j k}-q_{h j k}^{*}\right] \\
& +\sum_{j=1}^{J}\left[\sum_{h=1}^{H}\left(\sum_{i=1}^{I} q_{h i j}^{*}-\sum_{k=1}^{K} q_{h j k}^{*}\right)\right] \times\left[\gamma_{j}-\gamma_{j}^{*}\right] \geq 0 \\
& \forall\left(Q^{1}, Q^{3}, \gamma\right) \in R_{+}^{H I J+H J K+J}
\end{aligned}
$$


Here, the term $\gamma_{j}$ is the Lagrange multiplier associated with constraint (8), and $\gamma$ is an $J$-dimensional vector with component $\gamma_{j}$.

\section{c) The behaviour of exporters and their opti- mality conditions}

The exporters conduct transactions with both the local collectors and the local traders, from which they wish to obtain cocoa, as well as with the consumers who are the ultimate purchasers of cocoa. The behaviour of exporter $k$ who seeks a maximum profit can be formulated as follows:

$$
\begin{gathered}
\operatorname{Max}_{Q_{k}^{2}, Q_{k}^{3}, Q_{k}^{4}} \sum_{l=1}^{L} \rho_{k l}^{4 *} \sum_{h=1}^{H} q_{h k l}-c_{k}\left(Q^{2}, Q^{3}\right) \\
-g_{k}\left(Q^{2}, Q^{3}\right)-\sum_{l=1}^{L} c_{k l}\left(Q^{4}\right)-\sum_{h=1}^{H} \sum_{l=1}^{L} \rho_{h k l}^{4^{*}} q_{h k l} \\
-\sum_{j=1}^{J} \rho_{j k}^{3 *} \sum_{h=1}^{H} q_{h j k}-\sum_{k=1}^{K} \rho_{i k}^{2^{*}} \sum_{h=1}^{H} q_{h i k} \\
\text { subject to } \sum_{h=1}^{H} \sum_{l=1}^{L} q_{h k l} \leq \sum_{h=1}^{H} \sum_{i=1}^{I} q_{h i k}+\sum_{h=1}^{H} \sum_{j=1}^{J} q_{h j k} \\
q_{h i k} \geq 0 \quad \forall h, i, q_{h j k} \geq 0 \quad \forall h, j, q_{h k l} \geq 0 \forall h, l
\end{gathered}
$$

where,

$\rho_{k l}^{4} \quad:$ sales price charged for cocoa by exporter $k$ to demand market $l$,

$q_{h k l} \quad$ : amount of cocoa transacted/transported from exporter $k$ to demand market $l$ by freight carrier $h$, $c_{k}\left(Q^{2}, Q^{3}\right)$ : handling/inventory costs to exporter $k$, $g_{k}\left(Q^{2}, Q^{3}\right):$ facility cost to exporter $k$,

$c_{k l}\left(Q^{4}\right):$ transaction cost incurred between exporter $k$ and demand market $l$,

$\rho_{h k l}^{4}$

: carriage charged by freight carrier $h$ for transporting cocoa between exporter $k$ and demand market $l$,

$Q_{k}^{2}$

: $H I$-dimensional vector with component hik denoted by $q_{h i k}$,

$Q_{k}^{3}$

: $H J$-dimensional vector with component $h j k$ denoted by $q_{h j k}$,

$Q_{k}^{4} \quad: H L$-dimensional vector with compo$Q^{4}$ nent $h k l$ denoted by $q_{h k l}$,

: HKL-dimensional vector with component $h k l$ denoted by $q_{h k l}$.

Each exporter is assumed to face optimisation problem (11) subject to constraint (12) and nonnegativity assumption (13). Furthermore, exporters are assumed to compete in a noncooperative fashion. It could therefore be inferred that the exporters seek to determine not only the optimal amounts purchased by the consumers from their specific demand market, but also the amount that they wish to obtain from the local traders and local collectors.

Assuming that handling/inventory cost functions, facility cost functions and transaction cost functions are continuously differentiable and convex, the optimality conditions for all exporters can simultaneously be formulated as the following VI (14): determine $\left(Q^{2^{*}}, Q^{3^{*}}, Q^{4^{*}}, \delta^{*}\right) \in R_{+}^{H I K+H J K+H K L+K}$ satisfying:

$$
\begin{aligned}
& \sum_{h=1}^{H} \sum_{i=1}^{I} \sum_{k=1}^{K}\left[\frac{\partial c_{k}\left(Q^{2^{*}}, Q^{3^{*}}\right)}{\partial q_{h i k}}\right. \\
& \left.+\frac{\partial g_{k}\left(Q^{2^{*}}, Q^{3^{*}}\right)}{\partial q_{h i k}}+\rho_{i k}^{2^{*}}-\delta_{k}^{*}\right] \times\left[q_{h i k}-q_{h i k}^{*}\right] \\
& +\sum_{h=1}^{H} \sum_{j=1}^{J} \sum_{k=1}^{K}\left[\frac{\partial c_{k}\left(Q^{2^{*}}, Q^{3^{*}}\right)}{\partial q_{h j k}}+\frac{\partial g_{k}\left(Q^{2^{*}}, Q^{3^{*}}\right)}{\partial q_{h j k}}\right. \\
& \left.+\rho_{j k}^{3^{*}}-\delta_{k}^{*}\right] \times\left[q_{h j k}-q_{h j k}^{*}\right] \\
& +\sum_{h=1}^{H} \sum_{k=1}^{K} \sum_{l=1}^{L}\left[\frac{\partial c_{k l}\left(Q^{4^{*}}\right)}{\partial q_{h k l}}+\rho_{h k l}^{4^{*}}+\delta_{k}^{*}-\right. \\
& \left.\quad-\rho_{k l}^{4^{*}}\right] \times\left[q_{h k l}-q_{h k l}^{*}\right] \\
& +\sum_{k=1}^{K}\left[\sum_{h=1}^{H}\left(\sum_{i=1}^{I} q_{h i k}^{*}+\sum_{j=1}^{J} q_{h j k}^{*}-\sum_{l=1}^{L} q_{h k l}^{*}\right)\right] \times\left[\delta_{k}-\delta_{k}^{*}\right] \geq 0 \\
& \quad \forall\left(Q^{2}, Q^{3}, Q^{4}, \delta\right) \in R_{+}^{H I K+H J K+H K L+K}
\end{aligned}
$$

Here, the term $\delta_{k}$ is the Lagrange multiplier associated with constraint (12), and $\delta$ is $K$-dimensional vector denoted by $\delta_{k}$.

\section{d) The consumers in demand markets and the equilibrium conditions}

The consumers located at the demand markets are then discussed. The consumers take into account the prices charged for cocoa by the exporters in making their consumption decisions. Market demand describes the total quantity demanded by all consumers, which depends upon the demand market prices. The demand function is assumed to be continuous. Then, the following complementarity conditions hold for demand market $l$.

$$
\begin{gathered}
\rho_{k l}^{4^{*}} \begin{cases}=\rho_{l}^{5^{*}} & \text { if } q_{h k l}^{*}>0 \\
\geq \rho_{l}^{5^{*}} & \text { if } q_{h k l}^{*}=0\end{cases} \\
d_{l}\left(\rho^{5^{*}}\right)\left\{\begin{array}{l}
=\sum_{h=1}^{H} \sum_{k=1}^{K} q_{h k l}^{*} \text { if } \rho_{l}^{5^{*}}>0 \\
\leq \sum_{h=1}^{H} \sum_{k=1}^{K} q_{h k l}^{*} \text { if } \rho_{l}^{5^{*}}=0
\end{array}\right.
\end{gathered}
$$

$\rho_{l_{5}}^{5} \quad:$ market price of cocoa at demand market $l$,

$\rho^{5}: L$-dimensional vector with component $l$ denoted by $\rho_{l}^{5}$,

$d_{l}\left(\rho^{5}\right)$ : demand function at demand market $l$.

In equilibrium, conditions (15) and (16) will have to hold for all demand markets, and these, in turn, can also be expressed as a VI (17), and given by: determine $\left(Q^{4^{*}}, \rho^{5^{*}}\right) \in R_{+}^{H K L+L}$ such that: 


$$
\begin{aligned}
& \sum_{h=1}^{H} \sum_{k=1}^{K} \sum_{l=1}^{L}\left[\rho_{k l}^{4^{*}}-\rho_{l}^{5^{*}}\right] \times\left[q_{h k l}-q_{h k l}^{*}\right] \\
& +\sum_{l=1}^{L}\left[\sum_{h=1}^{H} \sum_{k=1}^{K} q_{h k l}^{*}-d_{l}\left(\rho^{5^{*}}\right)\right] \times\left[\rho_{l}^{5}-\rho_{l}^{5^{*}}\right] \geq 0 \\
& \forall\left(Q^{4}, \rho^{5}\right) \in R_{+}^{H K L+L}
\end{aligned}
$$

e) The behaviour of freight carriers and their optimality conditions

Assuming that the freight carriers are concerned with profit maximisation, thus optimisation problem for freight carrier $h$ can be formulated as:

$$
\begin{gathered}
\underset{Q_{h}^{1}, Q_{h}^{2}, Q_{h}^{3}, Q_{h}^{4}}{\operatorname{Max}} \sum_{i=1}^{I} \sum_{j=1}^{J} \rho_{h i j}^{1^{*}} q_{h i j}+\sum_{i=1}^{I} \sum_{k=1}^{K} \rho_{h i k}^{2^{*}} q_{h i k} \\
+\sum_{j=1}^{J} \sum_{k=1}^{K} \rho_{h j k}^{3^{*}} q_{h j k}+\sum_{k=1}^{K} \sum_{l=1}^{L} \rho_{h k l}^{4^{*}} q_{h k l} \\
-g_{h}\left(Q^{1}, Q^{2}, Q^{3}, Q^{4}\right)-w_{h}\left(Q^{1}, Q^{2}, Q^{3}, Q^{4}\right) \\
\text { subject to } q_{h i j} \geq 0 \forall i, j, \quad q_{h j k} \geq 0 \forall j, k, \\
q_{h k l} \geq 0 \forall k, l
\end{gathered}
$$

where,

$Q_{h}^{1}$ : IJ-dimensional vector with component $h i j$ denoted by $q_{h i j}$,

$Q_{h}^{2}$ : IK-dimensional vector with component hik denoted by $q_{h i k}$,

$Q_{h}^{3}: J K$-dimensional vector with component $h j k$ denoted by $q_{h j k}$,

$Q_{h}^{4}: K L$-dimensional vector with component $h k l$ $g_{h}\left(Q_{1}^{1}, Q^{2}, Q^{3}, Q^{4}\right)_{h k l}$ : facility cost of freight carrier $h$, $w_{h}\left(Q^{1}, Q^{2}, Q^{3}, Q^{4}\right)$ : operation cost of freight carrier $h$.

In case where the variability of travel time on the transport network is taken into consideration, the operation cost is assumed as the sum of average transport cost (i.e., $\bar{w}_{h}\left(Q^{1}, Q^{2}, Q^{3}, Q^{4}\right)$ ) and delay penalty cost. The operation costs of freight carrier are directly influenced by the conditions of TN. It is also assumed that the delay penalty cost is the cost incurred for avoiding substantial delay by the increased number of freight vehicles used and proportional to the amount of cocoa transported. According to existing study ${ }^{24)}$, the delay penalty cost can be calculated as follows.

Let $l_{h i j}^{+}$denote the maximum allowable travel time of freight carrier $h$ to transport the product from $i$ to $j$, where travel time $t_{h i j}$ is assumed to follow a probability distribution $\varphi_{h i j}(t)$. If the travel time is larger than the allowable travel time (i.e., $t\left(t \geq l_{h i j}^{+}\right)$), the delay time can thus be expressed as $\Delta_{h i j}^{+}=t-l_{h i j}^{+}$. Therefore, the expected delay time is estimated as follows:

$$
e_{h i j}^{+}\left(l_{h i j}^{+}\right) \equiv E\left(\Delta_{h i j}^{+}\right)=\int_{l_{h i j}^{+}}^{\infty}\left(t-l_{h i j}^{+}\right) \varphi_{h i j}(t) d t
$$

Let's define $\lambda_{h i j}^{+}\left(Q^{1}\right)$ as unit cost for delay penalty, and the expected delay penalty cost can be formulated as follows:

$$
E\left(\lambda_{h i j}^{+} \Delta_{h i j}^{+}\right)=\lambda_{h i j}^{+}\left(Q^{1}\right) e_{h i j}^{+}\left(l_{h i j}^{+}\right)
$$

Given $l_{h i j}^{+}$in advance, the delay penalty cost is only a function of $Q^{1}$. These also hold between $i$ and $j, i$ and $k, j$ and $k$ as well as between $k$ and $l$. Therefore, the operation cost of freight carriers can be described below:

$$
\begin{aligned}
w_{h}\left(Q^{1}, Q^{2}, Q^{3},\right. & \left.Q^{4}\right)=\bar{w}_{h}\left(Q^{1}, Q^{2}, Q^{3}, Q^{4}\right) \\
& +E\left(\lambda_{h i j}^{+} \Delta_{h i j}^{+}\right)+E\left(\lambda_{h i k}^{+} \Delta_{h i k}^{+}\right) \\
& +E\left(\lambda_{h j k}^{+} \Delta_{h j k}^{+}\right)+E\left(\lambda_{h k l}^{+} \Delta_{h k l}^{+}\right)
\end{aligned}
$$

Assuming that facility cost functions and operation cost functions (i.e., average transport cost functions and unit cost functions for delay penalty) are continuously differentiable and convex, the optimality conditions for all freight carriers can simultaneously be formulated as the following VI (23): determine $\left(Q^{1 *}, Q^{2^{*}}, Q^{3^{*}}, Q^{4^{*}}\right) \in R_{+}^{H I J+H I K+H J K+H K L}$ satisfying:

$$
\begin{gathered}
\sum_{h=1}^{H} \sum_{i=1}^{I} \sum_{j=1}^{J}\left[\frac{\partial g_{h}\left(Q^{1^{*}}, Q^{2^{*}}, Q^{3^{*}}, Q^{4^{*}}\right)}{\partial q_{h i j}}\right. \\
\left.+\frac{\partial w_{h}\left(Q^{1^{*}}, Q^{2^{*}}, Q^{3^{*}}, Q^{4^{*}}\right)}{\partial q_{h i j}}-\rho_{h i j}^{1^{*}}\right] \times\left[q_{h i j}-q_{h i j}^{*}\right] \\
+\sum_{h=1}^{H} \sum_{i=1}^{I} \sum_{k=1}^{K}\left[\frac{\partial g_{h}\left(Q^{1^{*}}, Q^{2^{*}}, Q^{3^{*}}, Q^{4^{*}}\right)}{\partial q_{h i k}}+\right. \\
\left.+\frac{\partial w_{h}\left(Q^{1^{*}}, Q^{2^{*}}, Q^{3^{*}}, Q^{4^{*}}\right)}{\partial q_{h i k}}-\rho_{h i k}^{2^{*}}\right] \times\left[q_{h i k}-q_{h i k}^{*}\right] \\
+\sum_{h=1}^{H} \sum_{j=1}^{J} \sum_{k=1}^{K}\left[\frac{\partial g_{h}\left(Q^{1^{*}}, Q^{2^{*}}, Q^{3^{*}}, Q^{4^{*}}\right)}{\partial q_{h j k}}\right. \\
\left.+\frac{\partial w_{h}\left(Q^{1^{*}}, Q^{2^{*}}, Q^{3^{*}}, Q^{4^{*}}\right)}{\partial q_{h j k}}-\rho_{h j k}^{3^{*}}\right] \times\left[q_{h j k}-q_{h j k}^{*}\right] \\
\forall\left(Q^{1}, Q^{2}, Q^{3}, Q^{4}\right) \in R_{+}^{H I J+H I K+H J K+H K L}
\end{gathered}
$$

\section{f) The equilibrium conditions of the supply chain network}

The equilibrium state of the supply chain network can be characterised as one where the optimality conditions (6), (10), (14), (17) and (23) hold simultaneously. The equilibrium conditions governing the model are equivalent to the solution to the VI given by: determine $\quad\left(Q^{1}, Q^{2}, Q^{3}, Q^{4}, \gamma, \delta, \rho^{4}\right) \in$ $R_{+}^{H I J+H I K+H J K+H K L+J+K+L}$

$$
\sum_{h=1}^{H} \sum_{i=1}^{I} \sum_{j=1}^{J}\left[\frac{\partial f_{i}\left(Q^{1^{*}}, Q^{2^{*}}\right)}{\partial q_{h i j}}+\frac{\partial c_{i}\left(Q^{1^{*}}, Q^{2^{*}}\right)}{\partial q_{h i j}}\right.
$$




$$
\begin{aligned}
& +\frac{\partial g_{i}\left(Q^{1^{*}}, Q^{2^{*}}\right)}{\partial q_{h i j}}-\gamma_{j}^{*}+\frac{\partial c_{i j}\left(Q^{1^{*}}\right)}{\partial q_{h i j}}+\frac{\partial c_{j}\left(Q^{1^{*}}\right)}{\partial q_{h i j}} \\
& +\frac{\partial g_{j}\left(Q^{1^{*}}\right)}{\partial q_{h i j}}+\frac{\partial g_{h}\left(Q^{1^{*}}, Q^{2^{*}}, Q^{3^{*}}, Q^{4^{*}}\right)}{\partial q_{h i j}} \\
& \left.+\frac{\partial w_{h}\left(Q^{1^{*}}, Q^{2^{*}}, Q^{3^{*}}, Q^{4^{*}}\right)}{\partial q_{h i j}}\right] \times\left[q_{h i j}-q_{h i j}^{*}\right] \\
& +\sum_{h=1}^{H} \sum_{i=1}^{I} \sum_{k=1}^{K}\left[\frac{\partial f_{i}\left(Q^{1^{*}}, Q^{2^{*}}\right)}{\partial q_{h i k}}+\frac{\partial c_{i}\left(Q^{1^{*}}, Q^{2^{*}}\right)}{\partial q_{h i k}}\right. \\
& +\frac{\partial g_{i}\left(Q^{1^{*}}, Q^{2^{*}}\right)}{\partial q_{h i k}}-\delta_{k}^{*}+\frac{\partial c_{i k}\left(Q^{2^{*}}\right)}{\partial q_{h i k}}+\frac{\partial c_{k}\left(Q^{2^{*}}, Q^{3^{*}}\right)}{\partial q_{h i k}} \\
& +\frac{\partial g_{k}\left(Q^{2^{*}}, Q^{3^{*}}\right)}{\partial q_{h i k}}+\frac{\partial g_{h}\left(Q^{1^{*}}, Q^{2^{*}}, Q^{3^{*}}, Q^{4^{*}}\right)}{\partial q_{h i k}} \\
& \left.+\frac{\partial w_{h}\left(Q^{1^{*}}, Q^{2^{*}}, Q^{3^{*}}, Q^{4^{*}}\right)}{\partial q_{h i k}}\right] \times\left[q_{h i k}-q_{h i k}^{*}\right] \\
& +\sum_{h=1}^{H} \sum_{j=1}^{J} \sum_{k=1}^{K}\left[\frac{\partial c_{k}\left(Q^{2^{*}}, Q^{3^{*}}\right)}{\partial q_{h j k}}+\frac{\partial g_{k}\left(Q^{2^{*}}, Q^{3^{*}}\right)}{\partial q_{h j k}}\right. \\
& +\frac{\partial c_{j k}\left(Q^{3^{*}}\right)}{\partial q_{h j k}}+\gamma_{j}^{*}-\delta_{k}^{*}+\frac{\partial g_{h}\left(Q^{1^{*}}, Q^{2^{*}}, Q^{3^{*}}, Q^{4^{*}}\right)}{\partial q_{h j k}} \\
& \left.+\frac{\partial w_{h}\left(Q^{1^{*}}, Q^{2^{*}}, Q^{3^{*}}, Q^{4^{*}}\right)}{\partial q_{h j k}}\right] \times\left[q_{h j k}-q_{h j k}^{*}\right] \\
& +\sum_{h=1}^{H} \sum_{k=1}^{K} \sum_{l=1}^{L}\left[\frac{\partial c_{k l}\left(Q^{4^{*}}\right)}{\partial q_{h k l}}+\frac{\partial g_{h}\left(Q^{1^{*}}, Q^{2^{*}}, Q^{3^{*}}, Q^{4^{*}}\right)}{\partial q_{h k l}}\right. \\
& \left.+\frac{\partial w_{h}\left(Q^{1^{*}}, Q^{2^{*}}, Q^{3^{*}}, Q^{4^{*}}\right)}{\partial q_{h k l}}+\delta_{k}^{*}-\rho_{l}^{5^{*}}\right] \times\left[q_{h k l}-q_{h k l}^{*}\right] \\
& +\sum_{j=1}^{J}\left[\sum_{h=1}^{H}\left(\sum_{i=1}^{I} q_{h i j}^{*}-\sum_{k=1}^{K} q_{h j k}^{*}\right)\right] \times\left[\gamma_{j}-\gamma_{j}^{*}\right] \\
& +\sum_{k=1}^{K}\left[\sum_{h=1}^{H}\left(\sum_{i=1}^{I} q_{h i k}^{*}+\sum_{j=1}^{J} q_{h j k}^{*}-\sum_{l=1}^{L} q_{h k l}^{*}\right)\right] \times\left[\delta_{k}-\delta_{k}^{*}\right] \\
& +\sum_{l=1}^{L}\left[\sum_{h=1}^{H} \sum_{k=1}^{K} q_{h k l}^{*}-d_{l}\left(\rho^{5^{*}}\right)\right] \times\left[\rho_{l}^{5}-\rho_{l}^{5^{*}}\right] \\
& \forall\left(Q^{1}, Q^{2}, Q^{3}, Q^{4}, \gamma, \delta, \rho^{5}\right) \in R_{+}^{H I J+H I K+H J K+H K L+J+K+L}
\end{aligned}
$$

Both the functional forms and parameter values of $f_{i}, c_{i}, c_{j}, c_{k}, c_{i j}, c_{i k}, c_{j k}, c_{k l}, g_{i}, g_{j}, g_{k}, g_{h}$, $\bar{w}_{h}, d_{l}, \varphi_{h i j}, \varphi_{h i k}, \varphi_{h j k}, \varphi_{h k l}, \lambda_{h i j}^{+}, \lambda_{h j k}^{+}, \lambda_{h j k}^{+}$, $\lambda_{h k l}^{+}, l_{h i j}^{+}, l_{h i k}^{+}, l_{h j k}^{+}$and $l_{h k l}^{+}$are predetermined on the basis of the existing studies so that the existence and uniqueness of the solutions are ensured. (Nagurney et al. ${ }^{6}$ and Yamada et al. ${ }^{7)}$ ).

Assuming $Z \equiv\left(Q^{1}, Q^{2}, Q^{3}, Q^{4}, \gamma, \delta, \rho^{5}\right) \quad$ and $G(u, Z) \equiv\left(G_{h i j}, G_{h j k}, G_{h i k}, G_{h k l}, G_{j}, G_{k}, G_{l}\right)$, as well as assuming that the specific components of $G$ are given by the functional terms preceding the multiplication signs in VI (24), the VI can be rewritten as
VI (3). In addition, VI (24) can be solved by the same solution procedures as those demonstrated in Yamada et al. ${ }^{7)}$.

\section{g) Retrieving the price variables}

The price variables $\rho_{i j}^{1}$ and $\rho_{i k}^{2}$ can be retrieved from the eventual solution by Equations (25) and (26), respectively, setting $q_{h i j}>0$ and $q_{h i k}>0$ in inequality (6).

$$
\begin{aligned}
\rho_{i j}^{1^{*}}= & \frac{\partial f_{i}\left(Q^{1^{*}}, Q^{2^{*}}\right)}{\partial q_{h i j}}+\frac{\partial c_{i}\left(Q^{1^{*}}, Q^{2^{*}}\right)}{\partial q_{h i j}} \\
& +\frac{\partial g_{i}\left(Q^{1^{*}}, Q^{2^{*}}\right)}{\partial q_{h i j}}+\frac{\partial c_{i j}\left(Q^{1^{*}}\right)}{\partial q_{h i j}}+\rho_{h i j}^{1^{*}} \\
\rho_{i k}^{2^{*}}= & \frac{\partial f_{i}\left(Q^{1^{*}}, Q^{2^{*}}\right)}{\partial q_{h i k}}+\frac{\partial c_{i}\left(Q^{1^{*}}, Q^{2^{*}}\right)}{\partial q_{h i k}} \\
& +\frac{\partial g_{i}\left(Q^{1^{*}}, Q^{2^{*}}\right)}{\partial q_{h i k}}+\frac{\partial c_{i k}\left(Q^{2^{*}}\right)}{\partial q_{h i k}}+\rho_{h i k}^{2^{*}}
\end{aligned}
$$

The equilibrium solutions of $\gamma, \delta$ can be obtained from inequality (24), and the prices $\rho_{j k}^{3}$ can also be obtained by finding a $q_{h j k}>0$ in inequality (10) as follows:

$$
\rho_{j k}^{3^{*}}=\frac{\partial c_{j k}\left(Q^{3^{*}}\right)}{\partial q_{h j k}}+\rho_{h j k}^{3^{*}}+\gamma_{j}^{*}
$$

Also, if $q_{h k l}>0$ in inequality (14), the $\rho_{k l}^{4}$ can be derived as Equation (28).

$$
\rho_{k l}^{4^{*}}=\frac{\partial c_{k l}\left(Q^{4^{*}}\right)}{\partial q_{h k l}}+\rho_{h k l}^{4^{*}}+\delta_{k}^{*}
$$

Furthermore, in the same way, from Equation (23), the carriages charged by freight carrier can be obtained as follows:

$$
\begin{aligned}
\rho_{h i j}^{1^{*}}= & \frac{\partial g_{h}\left(Q^{1^{*}}, Q^{2^{*}}, Q^{3^{*}}, Q^{4^{*}}\right)}{\partial q_{h i j}} \\
& +\frac{\partial w_{h}\left(Q^{1^{*}}, Q^{2^{*}}, Q^{3^{*}}, Q^{4^{*}}\right)}{\partial q_{h i j}} \\
\rho_{h i k}^{2^{*}} & =\frac{\partial g_{h}\left(Q^{1^{*}}, Q^{2^{*}}, Q^{3^{*}}, Q^{4^{*}}\right)}{\partial q_{h i k}} \\
& +\frac{\partial w_{h}\left(Q^{1^{*}}, Q^{2^{*}}, Q^{3^{*}}, Q^{4^{*}}\right)}{\partial q_{h i k}} \\
\rho_{h j k}^{3^{*}} & =\frac{\partial g_{h}\left(Q^{1^{*}}, Q^{2^{*}}, Q^{3^{*}}, Q^{4^{*}}\right)}{\partial q_{h j k}} \\
& +\frac{\partial w_{h}\left(Q^{1^{*}}, Q^{2^{*}}, Q^{3^{*}}, Q^{4^{*}}\right)}{\partial q_{h j k}} \\
\rho_{h k l}^{4^{*}} & =\frac{\partial g_{h}\left(Q^{1^{*}}, Q^{2^{*}}, Q^{3^{*}}, Q^{4^{*}}\right)}{\partial q_{h k l}}
\end{aligned}
$$




$$
+\frac{\partial w_{h}\left(Q^{1^{*}}, Q^{2^{*}}, Q^{3^{*}}, Q^{4^{*}}\right)}{\partial q_{h k l}}
$$

\section{(3) Upper level problem}

The efficiency of SCNs can be assessed using total surplus being calculated as the sum of producer surplus and consumer surplus. The producer surplus is estimated as the sum of the profits for all local collectors, all local traders, all exporters and all freight carriers, which can be computed with the solutions obtained by solving the multi-channelled cocoa SCNE. Therefore, the objective function of the upper level is to maximise the rate of profit, namely, the ratio of the increased total surplus on the SCN to the investment/operational costs required for implementing the TN improvement actions. However, the analyses to be presented in the paper are only preliminary, because the future profit of cocoa SCN have hardly been estimated accurately due to the uncertainty on the price as well as on the production. The future research should thus be conducted by taking into account such uncertainties as well as the project life and discount rates. The rate of profit can be used for assessing the impact of transport network improvement actions to on the efficiency of SCNs, where it takes into account not only the benefit/profit gained from the actions, but also the cost for implementing the actions. Let $A$ be defined as the link set in the SCN where

$$
\begin{aligned}
A= & {\left[a_{111}^{1}, \ldots, a_{h i j}^{1}, \ldots, a_{H I J}^{1}, a_{111}^{2}, \ldots, a_{h i k}^{2}, \ldots, a_{H I K}^{2},\right.} \\
& \left.a_{111}^{3}, \ldots, a_{h j k}^{3}, \ldots, a_{H J K}^{3}, a_{111}^{4}, \ldots, a_{h k l}^{4}, \ldots, a_{H K L}^{4}\right],
\end{aligned}
$$

and denoted $\varpi$ as a transport link for transporting and distributing cocoa. Each SCN link (see Fig. 1, for example) is associated with a single or a combination of transport links, since the freight carriers used some transport links for transporting cocoa. Then, the conditions in transport link $\varpi$ (e.g., its capacity and travel speed) directly influence the operation cost of freight carriers (Eq. 22). Therefore, let $W$ be defined as $W=W_{1} \cup W_{2}$, where $W_{1}$ is the set of existing transport links without any modifications, and $W_{2}$ is the set of transport links with possible actions to be implemented. Here $u_{\sigma}$ and $u$ are defined as $u_{\sigma} \in\{0,1\}$ and $u \in\left\{u_{\varpi} \mid \varpi \in W_{2}\right\}$, respectively, so that, $u_{\sigma}$ is equal to 1 if transport link $\varpi$ is built/renovated, otherwise $u_{\sigma}$ is 0 .

The objective function can be represented as follows:

$$
P\left(u, Z^{*}\right)=\frac{\left(U\left(u, Z^{*}\right)-U_{0}\left(Z^{*}\right)\right)}{\sum_{\pi \in W_{2}} \vartheta_{\varpi} u_{\varpi}}
$$

where,

$$
\begin{aligned}
& U\left(u, Z^{*}\right)= \\
& \sum_{i=1}^{I}\left[\sum_{j=1}^{J} \rho_{i j}^{1^{*}} \sum_{h=1}^{H} q_{h i j}+\sum_{k=1}^{K} \rho_{i k}^{2^{*}} \sum_{h=1}^{H} q_{h i k}-f_{i}\left(Q^{1^{*}}, Q^{2^{*}}\right)\right. \\
& -c_{i}\left(Q^{1^{*}}, Q^{2^{*}}\right)-g_{i}\left(Q^{1^{*}}, Q^{2^{*}}\right)-\sum_{j=1}^{J} c_{i j}\left(Q^{1^{*}}\right) \\
& \left.-\sum_{k=1}^{K} c_{i k}\left(Q^{2^{*}}\right)-\sum_{h=1}^{H} \sum_{j=1}^{J} \rho_{h i j}^{1^{*}} q_{h i j}-\sum_{h=1}^{H} \sum_{k=1}^{K} \rho_{h i k}^{2^{*}} q_{h i k}\right] \\
& +\sum_{j=1}^{J}\left[\sum_{k=1}^{K} \rho_{j k}^{3^{*}} \sum_{h=1}^{H} q_{h j k}-c_{j}\left(Q^{1^{*}}\right)-g_{j}\left(Q^{1^{*}}\right)\right. \\
& \left.-\sum_{k=1}^{K} c_{j k}\left(Q^{3^{*}}\right)-\sum_{h=1}^{H} \sum_{k=1}^{K} \rho_{h j k}^{3^{*}} q_{h j k}-\sum_{i=1}^{I} \rho_{i j}^{1^{*}} \sum_{h=1}^{H} q_{h i j}\right] \\
& +\sum_{k=1}^{K}\left[\sum_{l=1}^{L} \rho_{k l}^{4^{*}} \sum_{h=1}^{H} q_{h k l}-c_{k}\left(Q^{2^{*}}, Q^{3^{*}}\right)-g_{k}\left(Q^{2^{*}}, Q^{3^{*}}\right)\right. \\
& -\sum_{l=1}^{L} c_{k l}\left(Q^{4^{*}}\right)-\sum_{h=1}^{H} \sum_{l=1}^{L} \rho_{h k l}^{4 *} q_{h k l}-\sum_{j=1}^{J} \rho_{j k}^{3^{*}} \sum_{h=1}^{H} q_{h j k} \\
& \left.-\sum_{k=1}^{K} \rho_{i k}^{2 *} \sum_{h=1}^{H} q_{h i k}\right] \\
& +\sum_{h=1}^{H}\left[\sum_{i=1}^{I} \sum_{j=1}^{J} \rho_{h i j}^{1^{*}} q_{h i j}+\sum_{i=1}^{I} \sum_{k=1}^{K} \rho_{h i k}^{2^{*}} q_{h i k} \sum_{j=1}^{J} \sum_{k=1}^{K} \rho_{h j k}^{3^{*}} q_{h j k}\right. \\
& +\sum_{k=1}^{K} \sum_{l=1}^{L} \rho_{h k l}^{4^{*}} q_{h k l}-g_{h}\left(Q^{1^{*}}, Q^{2^{*}}, Q^{3^{*}}, Q^{4^{*}}\right) \\
& \left.-w_{h}\left(Q^{1^{*}}, Q^{2^{*}}, Q^{3^{*}}, Q^{4^{*}}, u\right)\right] \\
& +\sum_{l=1}^{L}\left[\int_{\rho_{l}^{5^{*}}}^{\rho_{l}^{5}} d_{l}\left(\rho^{5}\right) d \rho_{l}^{5}\right] \\
& U(\bullet) \text { : total surplus obtained in SCNs with actions } \\
& \text { implemented, }
\end{aligned}
$$

PSO is originally designed as optimisation technique for use in real-number spaces ${ }^{25}$. Kennedy and Eberhart $^{26)}$ then extended the continuous PSO to deal with discrete optimisation problems, which is also known as the discrete binary PSO (DBPSO). Menhas et al. ${ }^{27,28)}$ and Wang et al. ${ }^{29)}$ proposed the probability-based discrete binary PSO (PBPSO) algorithm. Recently, Zukhruf et al. ${ }^{23)}$ proposed the modified PBPSO (MPBPSO) algorithm, where an updating strategy for the change in position is embedded in the existing PBPSO algorithm. Results of the numerical tests show that the MPBPSO could provide better performance as compared to the conventional PBPSO algorithms (See the detailed algorithms in Zukhruf et al. ${ }^{23)}$ ).

The set of combination actions is determined in the 
upper level, where PSO is applied as solution techniques. The combination of improvement actions, $u$, is regarded as a particle of PSO, where its dimension represents the total number of possible actions to be implemented. The length of the particle is assumed to be 16 .

Every position of a particle, namely action implementation indicator $u_{\sigma}$, is formed in such a way that it takes a binary value of 1 if the corresponding action is implemented and 0 if it is otherwise. The value of objective function is calculated for each particle, and its fitness is evaluated. The swarm consists of a specific number of sets of actions. Settings of parameters used for MPBPSO are described in detail in Zukhruf et al. ${ }^{23)}$

\section{CASE STUDY SETTINGS}

The model developed is then numerically tested to validate its performance using a network as shown in Fig.2. Assuming that $\varphi_{h i \dot{u}}$ follows the normal distribution (i.e, $\varphi_{h i j} \sim N\left(t_{h i j}, \sigma_{h i j}^{2}\right)$ ), where $t_{h i j}$ and $\sigma_{h i j}^{2}$ denote the average and standard deviation of the travel time, respectively. The average travel time is set according to the distance and road conditions, where the data of road conditions (e.g., capacity, speed, traffic volume, etc.) are obtained from the database of the Indonesian Integrated Road Management System (IRMS).

In addition, the standard deviation is determined based on the actual data, which is surveyed in the Sulawesi Island, and these also hold for $\varphi_{h i k}, \varphi_{h j k}$ and $\varphi_{h k l}$. It is assumed that freight carriers consider the variability of travel time. Furthermore, allowable travel time $l_{h i j}^{+}$may vary depending on average travel time $t_{h i j}$. Thus, $l_{h i j}^{+}$is set as $l_{h i j}^{+}=\bar{t}_{h i j}+2 \sigma_{h i j}$. These assumptions also hold between $i$ and $k, j$ and $k$, and $k$ and $l$ as well.

As described above, the case studies to be carried out in this paper may lead to the unrealistic results, since the outputs depend on the configuration of so many functional forms and parameter values. Therefore, in order to represent the actual conditions of the cocoa SCN, the functional forms and parameter values are calibrated using the results of the logistics cost survey to export industries and the cocoa stakeholders ${ }^{4-5), 16), 36)-39)}$. In addition, to facilitate the better interpretation of the results, the actual cities are set as can be seen in Fig.2, and the parameter values are set by considering the location of such cities. The actual cities are located in the Sulawesi
Island, which is the biggest cocoa producer in Indonesia ${ }^{2)}$.

The local collectors usually operate in the farmers regions, as indicated by Syahruddin and Kalchschmidt $^{30)}$. Therefore, we set the local collectors to be located in the sub-district. In general, the local traders can be found not only in the sub-district, but also in regency/city, even though the biggest trader is mostly located in the capital of regency/city. Moreover, the exporters are mainly located in the capital of province. The overseas markets are typically set in the European region (i.e., Rotterdam), American region (i.e., New Jersey), and Asian region (i.e., Shanghai). Furthermore, we assume that the exporters transport cocoa to overseas market through the nearest seaport, which is located in Makassar, Palu and Kendari. The information of seaports are gathered from the related documents of Indonesian seaport $^{31)-34)}$. The functions used in the case studies are described as follows:

$$
\begin{gathered}
f_{i}=1000\left(\sum_{h=1}^{2}\left(\sum_{j=1}^{4} q_{h i j}+\sum_{k=1}^{3} q_{h i k}\right)\right) \\
c_{i}=\left(\sum_{h=1}^{2} \sum_{j=1}^{4} q_{h i j}+\left(\sum_{h=1}^{2} \sum_{k=1}^{3} q_{h i k}\right)^{1.4}\right)^{1.6} \\
c_{j}=0.5\left(\sum_{h=1}^{2} \sum_{i=1}^{4} q_{h i j}\right)^{1.4} \\
c_{k}=3.0\left(\sum_{h=1}^{2}\left(\sum_{j=1}^{4} q_{h j k}+\sum_{i=1}^{4} q_{h i k}\right)\right)^{1.4} \\
c_{i j}=15\left(\sum_{h=1}^{2} q_{h i j}\right) \\
c_{i k}=15\left(\sum_{h=1}^{2} q_{h i k}\right) \\
c_{j k}=15\left(\sum_{h=1}^{2} q_{h j k}\right) \\
c_{k l}=20\left(\sum_{h=1}^{2} q_{h k l}\right) \\
g_{i}=15\left(\sum_{h=1}^{2}\left(\sum_{j=1}^{2} \sum_{h=1}^{4} \sum_{h=1}^{4} q_{h j i}+\sum_{h=1}^{4} q_{h i j}\right)\right)
\end{gathered}
$$




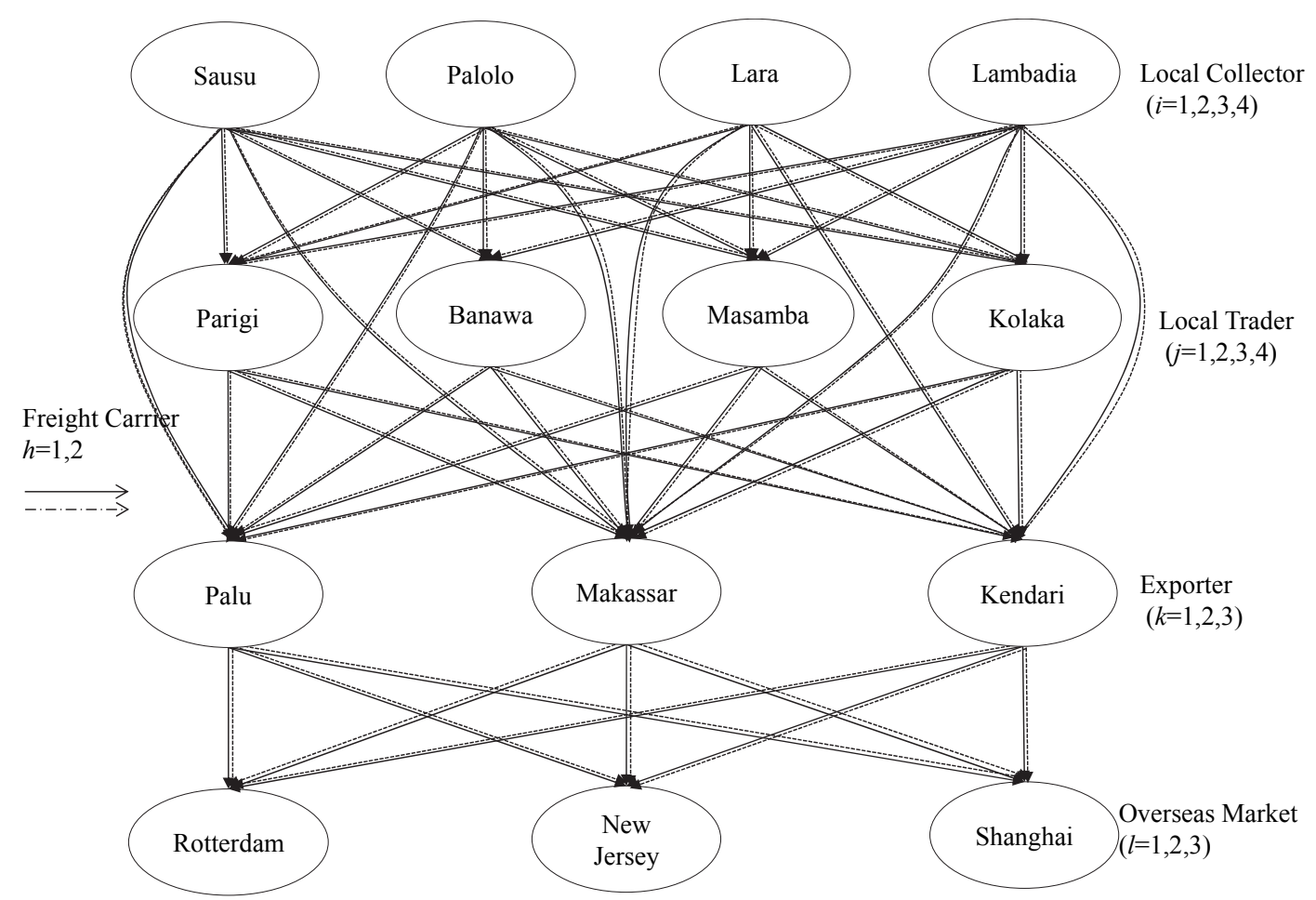

Fig. 2 Test SCN.

$$
\begin{aligned}
g_{h}= & 15\left(\sum_{i=1}^{4} \sum_{j=1}^{4} q_{h i j}+\sum_{i=1}^{4} \sum_{k=1}^{3} q_{h i k}\right. \\
& \left.+\sum_{j=1}^{4} \sum_{k=1}^{3} q_{h j k}+\sum_{k=1}^{3} \sum_{l=1}^{3} q_{h k l}\right) \\
= & \sum_{i=1}^{4} \sum_{j=1}^{4}\left(\beta_{h i j} q_{h i j}^{2}+\alpha_{h i j} q_{h i j}\right) \\
& +\sum_{i=1}^{4} \sum_{k=1}^{3}\left(\beta_{h i k} q_{h i k}^{2}+\alpha_{h i k} q_{h i k}\right) \\
& +\sum_{j=1}^{4} \sum_{k=1}^{3}\left(\beta_{h j k} q_{h j k}^{2}+\alpha_{h j k} q_{h j k}\right) \\
& +\sum_{k=1}^{3} \sum_{l=1}^{3}\left(\beta_{h k l} q_{h k l}^{2}+\alpha_{h k l} q_{h k l}\right) \\
i_{h i j}^{+}(Q)=50 & q_{h i j}\left(\text { also hold for } \lambda_{h i k}^{+}, \lambda_{h j k}^{+}, \lambda_{h k l}^{+}\right) \\
\sigma_{h i j}= & 0.2 \bar{t}_{h i j}\left(\text { also hold for } \sigma_{h i k}, \sigma_{h j k}\right) \\
\sigma_{h k l}=0.17 \bar{t}_{h k l} & \left\{\begin{array}{l}
1.5\left(1000-0.5 \rho_{l}^{5}\right) \quad \text { if } l=1 \\
2.0\left(1000-0.5 \rho_{l}^{5}\right) \quad \text { if } l=2 \\
0.4\left(1000-0.5 \rho_{l}^{5}\right) \quad \text { if } l=3
\end{array}\right.
\end{aligned}
$$

\begin{tabular}{|c|c|c|c|c|}
\hline$i \backslash j$ & 1 & 2 & 3 & 4 \\
\hline 1 & 1.0 & 2.0 & 6.5 & 9.0 \\
\hline 2 & 2.5 & 1.0 & 5.5 & 10.5 \\
\hline 3 & 7.0 & 4.0 & 0.5 & 15.0 \\
\hline 4 & 7.0 & 9.5 & 14.5 & 1.0 \\
\hline$\overline{i \mid k}$ & 1 & 2 & 3 & 4 \\
\hline 1 & 2.0 & 0.5 & 5.5 & 10.0 \\
\hline 2 & 10.5 & 8.5 & 4.5 & 18.5 \\
\hline 3 & 8.5 & 11.5 & 12.0 & 2.5 \\
\hline jj|k & 1 & 2 & 3 & $\overline{4}$ \\
\hline 1 & 1.5 & 0.5 & 5.0 & 9.0 \\
\hline 2 & 9.5 & 8.0 & 4.0 & 17.5 \\
\hline 3 & 16.5 & 11.0 & 15.5 & 1.5 \\
\hline$k \mid l$ & 1 & 2 & 3 & \\
\hline 1 & 130.0 & 115.5 & 132.5 & \\
\hline 2 & 183.5 & 169.0 & 186.0 & \\
\hline 3 & 80.5 & 66.0 & 83.0 & \\
\hline
\end{tabular}

Denote the price and cost parameters (in Eqs. (25) - (32) and Eqs. (35) - (47)) are set in 10,000 Rp. Handling cost functions (Eqs. (36) - (38)) are assumed to be nonlinear, taking into account the congestion in inventory.

As reflected in Eq. (36), the local collectors incurs higher handling cost when they sell cocoa to the
Table 1 Parameters setting of $\alpha_{h i j}, \alpha_{h i k}, \alpha_{h j k}, \alpha_{h k l}$ (same as for $h=1,2)$.

exporter than to the local trader, since the exporters put a higher quality standard of cocoa. In addition, to determine the cocoa prices, the exporters usually reduce the initial price based on certain quality parameters (e.g., moisture content, bean count, percentage of waste, mouldiness, and clumped or flat beans) ${ }^{3)}$. Therefore, the local collectors need to make more effort in handling cocoa (i.e., sorting, drying, fermenting, etc.) when they are willing to transact with the exporters. Coupled with the transport infrastructure issue, these facts causes a small numbers of the local collectors directly sell cocoa to the export$\mathrm{ers}^{3)}$.

As shown in Table 1, the values of $\alpha_{h i j}, \alpha_{h i k}$, $\alpha_{h j k}, \alpha_{h k l}$ are set based on the average travel times. 
$\beta_{h i j}, \beta_{h i k}, \beta_{h j k}, \beta_{h k l}$ are set to 0.2 for the city which located in the Sulawesi Island, and 0.3 for otherwise. Prior to full computation, the SCNE model in the lower level is to be first validated. The estimated ratio of logistics-related costs (i.e., average logistics cost, and handling cost) to total sales will be compared to the actually observed data ${ }^{5), 16), 36)-38)}$. The ratio of average logistics costs (i.e., the sum of handling/inventory costs and carriage), altogether with local collectors, local traders and exporters, is estimated as $10.3 \%$, while the actual observed values as $11.7 \%$. In addition, the ratio of handling cost to total sales is estimated as $2.7 \%, 1.2 \%$ and $1.9 \%$ respectively, while the observed value as $2.3 \%, 0.8 \%$ and $1.7 \%$. for local collectors, local traders and exporters.

Furthermore, in order to represent the market size, the ratio of market shares between cities resulting from the model is then confirmed with the actual data $^{39)}$. As can be inferred from Fig.3, New Jersey is estimated as the biggest cocoa market, and then follows by Rotterdam and Shanghai. The estimated values are conformable with the observed ones. Since the model incorporates the international trading with high transport costs, the estimated ratio of transport cost to total sales for distributing cocoa from Makassar to the overseas market is to be compared to the actual observed values ${ }^{4)}$. As shown in Fig.4, the ratio of transport cost to total sales for transporting cocoa from Makassar to overseas destination is almost consistent with the observed data.

Generally, these results are consistent with the reality, even though it might not be sufficient to completely represent the real world. However, such attempts are crucial to demonstrate the reliability of estimates undertaken in this paper.

\section{APPLICATION RESULTS}

The applicability of the model is then be tested using the validated cocoa SCN and the freight transport improvement actions. 16 alternative actions listed in Table 2, modelled and located as shown in Fig.5-7, including road improvement, seaport improvement, establishment of new expressways and new railways are set as candidates, where the best combination of actions that maximises the rate of profit (e.g., the value of Eq. (33)) is to be selected as a solution.

The information relating to the establishment of new railways and expressways are acquired from the master plan documents of infrastructure development in Sulawesi Island ${ }^{31), 35)}$. Furthermore, the data of further development of Makassar seaport are collected from the master plan of Makassar Seaport ${ }^{32)}$.

Road improvement action includes the road pavement and improvement of capacity, which is increased 1.5 times the initial capacity. In the case of

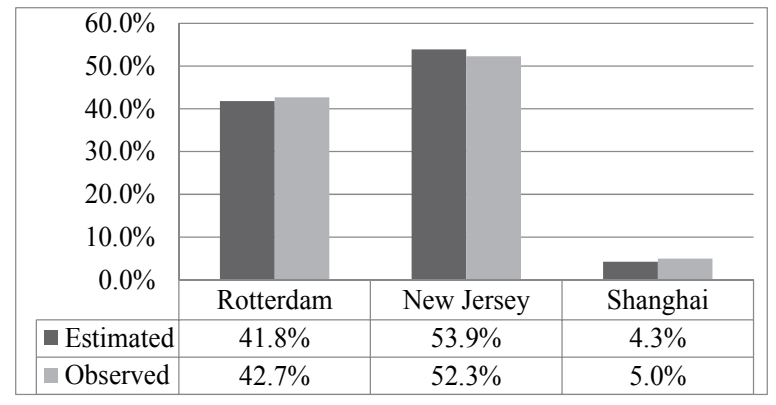

Fig. 3 Market shares of cocoa.

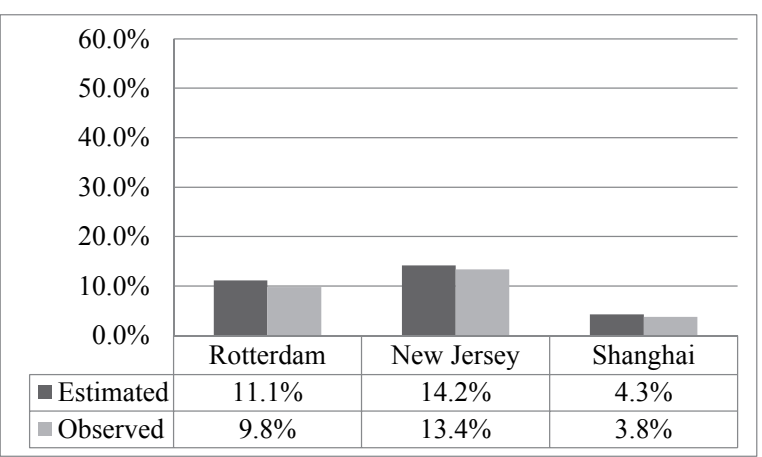

Fig. 4 The ratio of transport cost to total sales for distributing cocoa from Makassar to the overseas market.

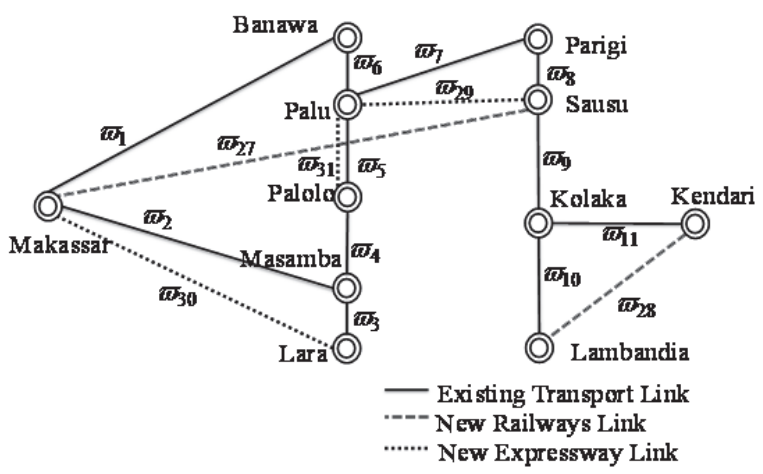

Fig. 5 Modelled road and railway network.

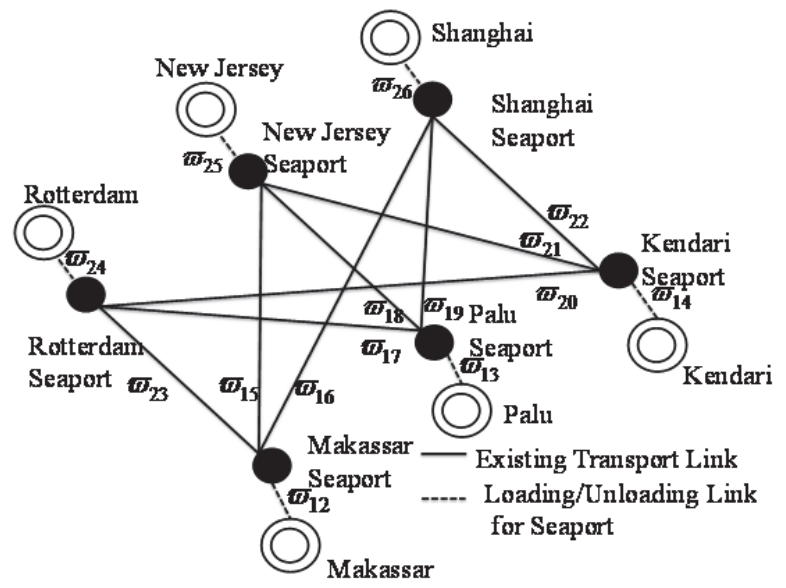

Fig. 6 Modelled sea lanes and seaport. 


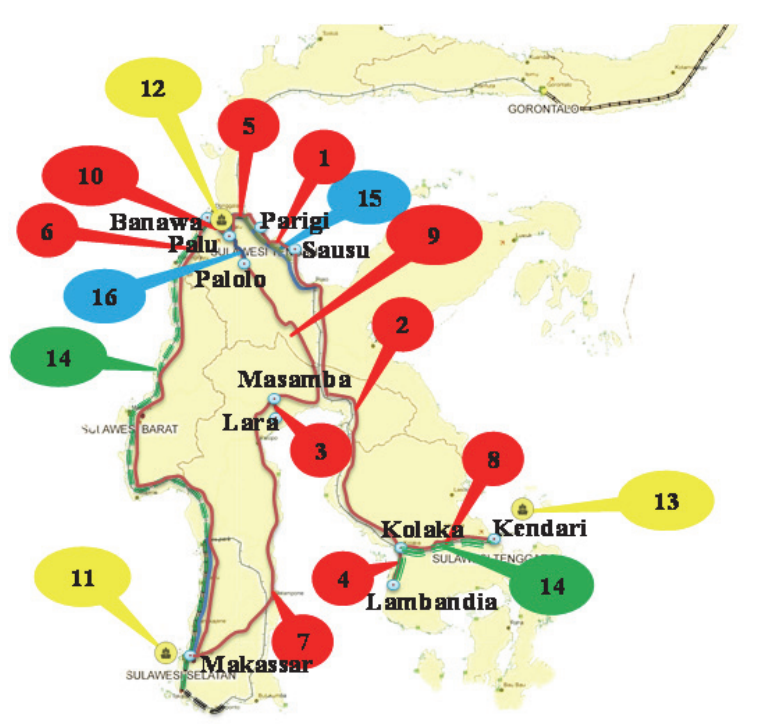

Road Improvement (Pavement, Capacity Impr. and etc) New Expressway

New Railway

Seaport Improvement

Fig. 7 Modelled transport network and actions.

seaport improvement, increased capacities are assumed to increase by $40.0 \%$ as compared to the initial capacity ${ }^{32)}$. Overall, the establishment of new expressways and railways is relatively more expensive, whereas road improvement is relatively cheaper compared with the other type of actions. The transport improvement action will improve the performance of the existing transport infrastructure (e.g., travel time for transport link, and loading/unloading time in for seaport). Hence, it directly affects the related-parameters of above operation costs of freight carriers.

As can be seen in the Fig.8, the rates of profit are all less than one. However, this seems plausible, since, in this research, the benefits are only estimated in terms of cocoa product, even though the implemented actions will surely affect not only the cocoa product but also the other products. In addition, this case study only takes into account 92,510.0-ton amount of cocoa, which is only $17.9 \%$ of total production of cocoa in Sulawesi.

The best solution is found to contain action numbers 1 and 10 for the road improvement actions. Although this combination of actions does not significantly increase the profit (i.e., surpluses), this only requires relatively small investment cost. The road improvement actions, which connects Sausu-Parigi (action no. 1) and Banawa-Palu (action no. 10), slightly increase the amount of cocoa transacted from Sausu and Banawa. The reduction of transport cost is mainly reason of this fact, where these actions lead to $2.0 \%$ reduction of transport cost for moving cocoa from Sausu as well as from Banawa to local traders or exporters. Hence, the road improvement in these areas could bring slightly larger profit to the entire cocoa SCN.

Fig. 8 compares the rates of profit and the cocoa-related profit for the optimal solution (i.e., actions 1 and 10), as well as for other sets of actions around it. This figure also intends to demonstrate the synergetic effect of action combination, as well as to show the cost effectiveness for implementing the action. Fig. 8 shows that the combination of road improvement and seaport improvement actions (i.e., actions 1, 10 and 11) can provide considerable profit to the cocoa SCN with relatively lower investment cost than establishing new railways and expressways.

This combination not only increase the efficiency for transporting cocoa in Sulawesi Island, but also reduce the transport cost for exporting cocoa to overseas demand markets, where the transport cost for exporting cocoa from Makassar decrease up to $6.5 \%$. The result is plausible, because the congestion in seaport terminal is regarded as an important factor driving up shipping costs ${ }^{4}$.

Fig. 8 also displays that set of actions 14, 15, and 16 offers the highest profit than other action sets, because the new infrastructure constructions (i.e., new railways and expressways) not only significantly reduce the transport costs for moving cocoa in Sulawesi, but also increase the amount cocoa transacted; even though these actions are not selected in the best set. This is largely due to significantly larger investment cost required for their establishment.

\section{CONCLUSION}

This paper presented a multi-channelled SCNE model with the behaviour of freight carriers, which is developed based on the existing SCNE model and being dedicated to the supply chain of cocoa. The SCNE model is taking into account the behaviour of cocoa SCN entities (i.e., local collectors, local traders, exporters, and freight carriers), which might be typical to other agricultural product chains. Since the local collectors are not involved in the producing process as well as they can practically make direct transaction to exporters, the collection costs and the multi-channelled SCN are incorporated in this paper.

The model was then extended to the framework of MPEC, where the cocoa-oriented SCNE is incorporated within the lower level, and the upper level approximately optimise the set of transport network improvement actions. A meta-heuristics method, called MPBPSO, was utilised for solving the upper level.

The results show that the road improvement actions would highly be desired for improving efficiency of cocoa SCN than the development of other infrastructures (i.e., seaports, expressways, rail ways) in terms of cost effectiveness on cocoa SCN. 
Table 2 Listing of actions.

\begin{tabular}{|r|l|l|l|r|r|}
\hline \multirow{2}{*}{ No } & \multirow{2}{*}{ Type of Action } & \multicolumn{2}{|c|}{ Location } & \multirow{2}{*}{$\begin{array}{c}\text { Dist. } \\
(\mathrm{km})\end{array}$} & $\begin{array}{r}\text { Inv./Op.Co } \\
\text { st (bil Rp.) }\end{array}$ \\
\cline { 3 - 4 } & \multicolumn{2}{|c|}{$($ Corresponding Links $)$} & 58.8 & 183.9 \\
\hline 1 & Road Improvement & $\varpi_{8}$ & Sausu-Parigi & 658.5 & 2061.0 \\
\hline 2 & Road Improvement & $\varpi_{9}$ & Sausu-Kolaka & 32.9 & 102.9 \\
\hline 3 & Road Improvement & $\varpi_{3}$ & Lara-Masamba & 79.9 & 250.1 \\
\hline 4 & Road Improvement & $\varpi_{10}$ & Lambadia-Kolaka & 93.2 & 291.7 \\
\hline 5 & Road Improvement & $\varpi_{7}$ & Parigi-Palu & 1062.2 & 3324.6 \\
\hline 6 & Road Improvement & $\varpi_{1}$ & Banawa-Makassar & 432.0 & 1352.2 \\
\hline 7 & Road Improvement & $\varpi_{2}$ & Masamba-Makassar & 432 & 566.7 \\
\hline 8 & Road Improvement & $\varpi_{11}$ & Kolaka-Kendari & 181.1 & 1230.6 \\
\hline 9 & Road Improvement & $\varpi_{4}$ & Palolo-Masamba & 393.2 & 105.5 \\
\hline 10 & Road Improvement & $\varpi_{6}$ & Banawa-Palu & 33.7 & 4119.5 \\
\hline 11 & Seaport Improvement & $\varpi_{21}$ & Makassar & - & 4943.4 \\
\hline 12 & Seaport Improvement & $\varpi_{22}$ & Palu & - & 6179.2 \\
\hline 13 & Seaport Improvement & $\varpi_{23}$ & Kendari & - & 61642.5 \\
\hline 14 & New Railway & $\varpi_{27}$ & Sausu-Makassar & 1247.8 & 3631.9 \\
\hline 15 & New Expressway & $\varpi_{29}$ & Sausu-Palu & 79.9 & 2636.1 \\
\hline 16 & New Expressway & $\varpi_{31}$ & Palolo-Palu & 58.0 & \\
\hline & & & & \\
\hline
\end{tabular}

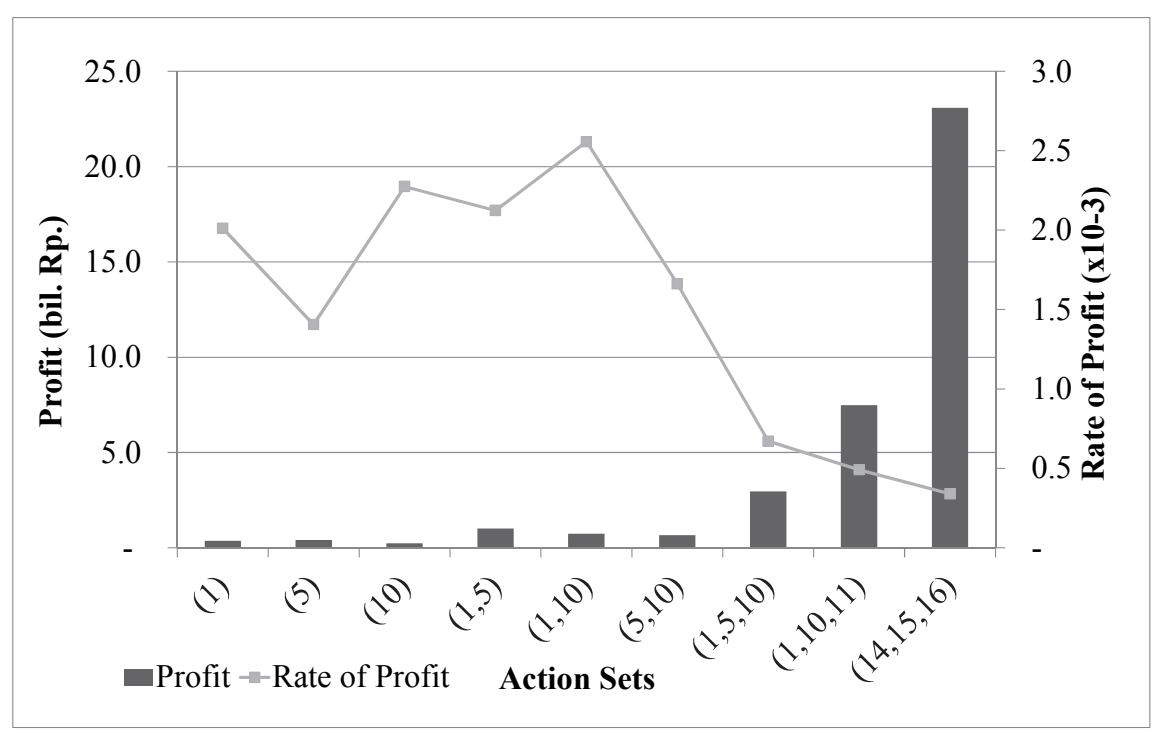

Fig. 8 Computational results comparison among action sets.

In addition, it is also indicated that the road and seaport improvement actions would have the potential to increase the efficiency with relatively lower investment cost than establishing new railways and expressways. However, these implications are merely derived through the case studies on cocoa, even though it is a very important agricultural product in Sulawesi. Accordingly, in order to obtain more comprehensive insights of freight transport planning, the further study needs to investigate the cost effectiveness considering the other types of products.

\section{REFERENCES}

1) The International Coffee and Cocoa Organisation (ICCO) : Production of cocoa beans, Quarterly Bulletin of Cocoa
Statistics, Vol. 39, No. 1, 2013.

2) Indonesian Ministry of Industry : Road map of development cocoa industry, 2010 (in Bahasa Indonesia).

3) Panlibuton, H. and Meyer, M. : Value chain assessment: Indonesia cocoa, ACDI / VOCA - USAID, 2004

4) Carana Corporation : Impact of transport and logistics on Indonesia's trade competetiveness, Paper for review by USAID, 2004.

5) The Asia Foundation and LPEM-FEUI : The cost of moving goods: road transportation, regulations and charges in Indonesia, 2008.

6) Nagurney, A., Dong, J. and Zhang, D. : A supply chain network equilibrium model, Transportation Research Part E, Vol. 38, No. 5, pp. 281-303, 2002.

7) Yamada, T., Imai, K., Nakamura, T. and Taniguchi, E. : A supply chain-transport supernetwork equilibrium model with behaviour of freight carriers, Transportation Research Part E, Vol. 47, No. 6, pp. 887-907, 2011.

8) Yamada, T., Imai, K. and Taniguchi, E. : Supply chain 
network equilibrium with the behaviour of freight carriers, Journal of Infrastructure Planning, Vol. 65, No. 2, pp. 163 174, 2009 (in Japanese).

9) Kinsey, J. D. : The new food economy: Consumers, farms, pharms and science, American Journal of Agricultural Economics, Vol. 83, No. 5, pp. 1113-1130, 2001.

10) Huang, S. W. : Global trade patterns in fruits and vegetables, United States Department of Agriculture, Agriculture and Trade Report, No. WRS-04-06, 2004.

11) Boehlje, M. : Structural changes in the agricultural industries: How do we measure, analyze and understand them?, American Journal of Agricultural Economics, Vol. 81, No. 5, pp. 108-1041, 1999.

12) Ahumada, O. and Villalobos, J. R. : Application of planning models in the agri-food supply chain: A review, European Journal of Operational Research, Vol. 196, No. 1, pp. 1-20, 2009.

13) Monteiro, D. M. S. : Theoretical and empirical analysis of the economics of traceability adoption in food supply chains, Ph.D. Thesis, University of Massachusetts Amherst, Amherst, MA, USA, 2007.

14) Panliburton, H. and Lusby, F. : Indonesia cocoa bean value chain case study, ACDI / VOCA - USAID, 2006.

15) Bedford, A., Blowfield, M., Burnett, D. and Greenhalgh, P. : Value chains: lessons from the Kenya tea and Indonesian cocoa sectors, International Business Leader Forum / Natural Research Institute, 2002.

16) The Institute for Economic and Social Research at the University of Indonesia (LPEM-FEUI): Inefficiency in the logistics of export industries: The case of Indonesia, Report in collaboration with Japan Bank for International Cooperation (JBIC), 2005.

17) $\mathrm{Yu}, \mathrm{M}$. and Nagurney, A. : Competitive food supply chain networks with application to fresh produce, European Journal of Operational Research, Vol. 224, No. 2, pp. 273282, 2013.

18) Gao, Z., Wu, J. and Sun, H. : Solution algorithm for the bi-level discrete network design problem, Transportation Research Part B, Vol. 39, No. 6, pp. 479-495, 2005.

19) Poorzahedy, H. and Turnquist, M. A. : Approximate algorithms for the discrete network design problem, Transportation Research Part B, Vol. 16, No.1, pp. 45-55, 1982.

20) Poorzahedy, H. and Rouhani, O. : Hybrid meta-heuristic algorithms for solving network design problem, European Journal of Operational Research, Vol. 182, No. 2, pp. 578596, 2007.

21) Steenbrink, A. : Transport network optimization in the Dutch integral transportation study, Transportation Research Part B, Vol. 8, No. 1, pp. 11-27, 1974.

22) Yamada, T. Russ, B. F., Castro, J. and Taniguchi, E. : Designing multimodal freight transport networks: A heuristic approach and applications, Transportation Science, Vol. 43, No. 2, pp. 129-143, 2009.

23) Zukhruf, F., Yamada, T. and Taniguchi, E. : Transport network design for enhancing the efficiency of supply chain networks, Proceedings of 4th International Conference on Transportation and Logistics, CD-ROM, 2012.

24) Taniguchi, E., Yamada, T. and Yasushi, K. : Probabilistic routing and scheduling of urban pickup/delivery trucks with variable travel times, Journal of JSCE, No. 674/IV-51, pp. 49-61, 2001 (in Japanese).

25) Eberhart, R. C. and Kennedy, J. : A new optimiser using particle swarm theory, Proceedings of the Sixth International Symposium on Micro Machine and Human Science, pp. 39-43, 1995.

26) Kennedy, J. and Eberhart, R. : A discrete binary version of the particle swarm algorithm, Proceedings of the IEEE International Conference on Systems, Man and Cybernetics, Vol. 5, pp. 4104-4108, 1997.

27) Menhas, M. I., Wang, L., Fei, M. and Pan, H. : Comparative performance analysis of various binary coded PSO algorithms in multivariable PID controller design, Expert Systems with Applications, Vol. 39, No. 4, pp. 4390-4401, 2012.

28) Menhas, M. I., Wang, L., Fei, M. and Ma, C. : Coordinated controller tuning of a boiler turbine unit with new binary particle swarm optimisation algorithm, International Journal of Automation and Computing, Vol. 8, No. 2, pp. 185-192, 2011.

29) Wang, L., Wang, X., Fu, J. and Zhen, L. : A novel probability binary particle swarm optimisation algorithm and its application, Journal of Software, Vol. 3, No. 9, pp. 28-35, 2008.

30) Syahruddin, N. and Kalchschmidt, M. : Traceability in the cocoa supply chain: an Indonesian context, Proceedings of POMS 23rd Annual Conference "Socially Responsible Operations", 2012.

31) Decentralization Support Facility (DSF): Strategic Planning of Sulawesi Island : Capacity building for Regional Development Policy, 2011 (in Bahasa Indonesia).

32) Indonesian Department of Communications : Master Plan of Makassar Seaport, 2012 (in Bahasa Indonesia).

33) Pelindo IV : Annual report of PT Pelabuhan Indonesia, 2010 (in Bahasa Indonesia).

34) AusAID: Draft of transportation ministry decree about the national master plan of Indonesian seaport, 2012 (in Bahasa Indonesia).

35) Indonesian Department of Communications : Master plan of Indonesia National Railway, 2011 (in Bahasa Indonesia).

36) Ali, D. and Rukka, R. M.: The role of cocoa trader in increasing market efficiency in South Sulawesi, Journal of Social and Agricultural Economics, Vol. 8, No. 1, 2011 (in Bahasa Indonesia).

37) Yantu, M. R. : Regional economic models of cocoa beans in Central Sulawesi, Ph.D. Thesis. Institut Pertanian Bogor, Bogor, Indonesia, 2011 (in Bahasa Indonesia).

38) Yantu, M. R., Juanda, B., Siregar, H., Gonarsyah, I. and Hadi, S. : Integration of cocoa bean at the rural markets in Central Sulawesi with the world market, Journal of Agro Economics, Vol. 28, No. 2, pp. 201-225, 2010.

39) International Trade Center : Exports of cocoa and cocoa preparations from Indonesia (2007-2011). <http://legacy. intracen.org/appli1/TradeCom/TP_EP_IC.aspx?IN=18\&Y $\mathrm{R}=2009>($ accessed 23.07.13)

(Received February 28, 2014) 